\title{
Left bundle branch block and coronary artery disease: Accuracy of dipyridamole thallium-201 single-photon emission computed tomography in patients with exercise anteroseptal perfusion defects
}

\author{
N. E. Lebtahi, MD, J. C. Stauffer, MD, and A. Bischof Delaloye, MD
}

Background. Reduced septal or anteroseptal uptake of thallium-201 during exercise is frequently observed in patients with left bundle branch block (LBBB) even in the absence of left anterior descending (LAD) coronary artery disease. The purpose of this study was to evaluate prospectively the accuracy of dipyridamole ${ }^{201} \mathrm{Tl}$ single-photon emission computed tomography (SPECT) in detecting LAD coronary artery disease in patients with LBBB and septal or anteroseptal perfusion defects on exercise ${ }^{201}$ TI SPECT.

Methods and Results. Twelve consecutive patients (10 men and two women) with complete LBBB and septal or anteroseptal perfusion defects on exercise ${ }^{201}$ TI SPECT underwent dipyridamole ${ }^{201}$ TI SPECT. The delay between dipyridamole and exercise was 2 to 30 days. Coronary angiography was performed during this period in all patients. Six $(50 \%)$ of 12 patients with exercise perfusion defects showed normal perfusion after dipyridamole; all had normal coronary angiograms. The remaining six patients also had positive results of dipyridamole studies, two with moderate and four with severe septal or anteroseptal perfusion defects. Coronary angiography showed significant $(>50 \%)$ LAD coronary artery stenosis in three patients; three patients with severe septal or anteroseptal perfusion defects after dipyridamole had normal coronary angiograms. Neither the evaluation of apical involvement nor the presence of dilated ventricles, decreased left ventricular ejection fraction, or wall motion abnormalities could help to identify (or explain) false-positive results.

Conclusion. This study confirms that dipyridamole is more accurate than exercise in excluding $L A D$ coronary artery disease. However, there are still false-positive results and the severity of the septal or anteroseptal perfusion defect does not add additional information to identify LAD coronary artery disease. Coronary angiography is thus necessary for positive dipyridamole study results to identify coronary artery disease as a major prognostic factor in patients with LBBB. (J Nucl Cardiol 1997;4:266-73.)

Key Words: left bundle branch block $\bullet$ dipyridamole $\bullet$ thallium-201 $\bullet$ single-photon emission computed tomography $\bullet$ coronary artery disease

The high frequency of septal or anteroseptal perfusion defects on exercise scintigraphy in patients with left bundle branch block (LBBB) in the absence of left anterior descending (LAD) coronary artery disease has been well documented. ${ }^{1-13}$ Cumulative results (Table 1)

From the Divisions of Nuclear Medicine and Cardiology, University Hospital, Lausanne, Switzerland.

Received for publication March 7, 1996; revision accepted Jan. 2, 1997.

Reprint requests: N. E. Lebtahi, MD, Centre d'Imagerie, CIMED, rue de Locarno 9, 1700 Fribourg, Switzerland.

Copyright $\odot 1997$ by American Society of Nuclear Cardiology.

$1071-3581 / 97 / \$ 5.00+0 \quad \mathbf{4 3 / 1 / 8 0 1 2 0}$ indicate that septal or anteroseptal perfusion defects were present in $73 \%$ of cases, whereas a significant LAD stenosis was shown by coronary angiography in only $42 \%$. Additional information in Table 1 indicates that the proportion of patients with LBBB and LAD coronary artery disease was only $38 \%$. A proposed mechanism for the perfusion defects in the presence of normal coronary arteries is the occurrence of "relative hypoperfusion" 2,6 caused by abnormal septal motion. Exercise by inducing tachycardia further shortens left ventricular diastole, which could explain the occurrence, as well as the reversibility, of the defects. Thus pharmacologic stress has been suggested to be a more accurate stimulus for the 
Table 1. Cumulative results with exercise scintigraphy in patients with LBBB who underwent coronary angiography

\begin{tabular}{|c|c|c|c|c|c|}
\hline Study & No. patients ${ }^{*}$ & Tracer & No. $S$ or AS + & No. TP & $\begin{array}{c}\text { No. LAD + } \\
\text { (total) }\end{array}$ \\
\hline Hirzel et al. ${ }^{2} 1984$ & 19 & ${ }^{201} \mathrm{Tl}$ & 19 & 4 & 4 \\
\hline Braat et al. ${ }^{31} 1985$ & 24 & ${ }^{201} \mathrm{Tl}$ & 7 & 6 & 11 \\
\hline Huerta et al. ${ }^{3} 1987$ & 11 & ${ }^{201} \mathrm{Tl}$ & 8 & 0 & 0 \\
\hline Rothbart et al. ${ }^{4} 1987$ & 22 & ${ }^{201} \mathrm{Tl}$ & 16 & 5 & 7 \\
\hline De Puey et al. ${ }^{5} 1988$ & 14 & ${ }^{201} \mathrm{Tl}$ & 12 & 3 & 4 \\
\hline Burns et al. ${ }^{\circ} 1991$ & 16 & ${ }^{201} \mathrm{Tl}$ & 12 & 5 & 6 \\
\hline Matzer et al. ${ }^{7} 1991$ & 44 & ${ }^{201} \mathrm{Tl}$ & 41 & 24 & 24 \\
\hline Larcos et al. ${ }^{8} 1991$ & 83 & ${ }^{201} \mathrm{Tl}$ & 56 & 26 & 38 \\
\hline La Canna et al. ${ }^{9} 1992$ & 33 & ${ }^{201} \mathrm{Tl}$ & 21 & 0 & 0 \\
\hline Delonca et al. ${ }^{10} 1992$ & 66 & ${ }^{201} \mathrm{Tl}$ & 45 & 16 & 17 \\
\hline Altehoefer et al. ${ }^{21} 1993$ & 9 & ${ }^{99 \mathrm{~m}}$ Tc-labeled sestamibi & 3 & 2 & 5 \\
\hline Knapp et al.22 1993 & 28 & ${ }^{201} \mathrm{TI}$ & 26 & 15 & 16 \\
\hline Knapp et al. 221993 & 37 & ${ }^{99 \mathrm{~m}}$ Tc-labeled sestamibi & 34 & 14 & 15 \\
\hline Ebersole et al. ${ }^{11} 1993$ & 11 & ${ }^{99 \mathrm{~m}}$ Tc-labeled sestamibi & 8 & 2 & 3 \\
\hline O'Keefe et al. ${ }^{12} 1993$ & 31 & ${ }^{201} \mathrm{Tl}$ & 20 & 11 & 15 \\
\hline Vaduganathan et al. ${ }^{13} 1996$ & 77 & ${ }^{201} \mathrm{Tl}$ & 57 & 29 & 33 \\
\hline Total & 525 & & $385(73 \%)$ & $162(42 \%)$ & $197(38 \%)$ \\
\hline
\end{tabular}

$S$ or AS+, Septal or anteroseptal perfusion defect; TP, true positive results ( $\mathrm{S}$ or AS+ and LAD disease); LAD+, significant LAD coronary artery stenosis.

${ }^{*}$ Only patients who underwent coronary angiography were considered.

detection of coronary artery disease by myocardial thallium-201 imaging in patients with LBBB. . $^{6,12-18} \mathrm{We}$ studied prospectively the value of dipyridamole in the identification of LAD coronary artery disease in patients with LBBB and septal or anteroseptal perfusion defects on exercise ${ }^{201} \mathrm{Tl}$ single-photon emission computed tomography (SPECT).

\section{METHODS}

Patients. Twelve consecutive patients (10 men and two women), aged 37 to 77 years (mean age 58 years), with complete LBBB and septal or anteroseptal perfusion defects on exercise ${ }^{201} \mathrm{Tl}$ SPECT underwent dipyridamole ${ }^{201} \mathrm{Tl}$ SPECT within 1 month. All 12 patients underwent coronary angiography for clinical reasons during this period. Shown in Table 2 are the clinical data of all patients.

Exercise Protocol. Patients underwent a symptom-limited Bruce protocol exercise test on a bicycle ergometer. At peak exercise, a weight-adjusted dose (range 2.5 to $3.5 \mathrm{mCi}$ ) of ${ }^{201} \mathrm{Tl}$ was administered intravenously and patients were encouraged to continue exercising for 1 to 2 minutes. SPECT imaging was performed as soon as possible after the end of exercise and again 3 to 4 hours after the ${ }^{201} \mathrm{Tl}$ injection.

Dipyridamole Protocol. Patients were advised to avoid food and caffeine-containing drinks for the 12 hours preceding the test. All patients had a 4-minute intravenous infusion of $0.56 \mathrm{mg} / \mathrm{kg}$ dipyridamole. Cardiac rhythm was monitored continuously, and 12-lead electrocardiogram, blood pressure, and heart rate were obtained every 2 minutes during the test. Three minutes after the end of dipyridamole infusion, a weight-adjusted dose of ${ }^{201} \mathrm{Tl}$ (range 2.5 to $3.5 \mathrm{mCi}$ ) was administered and SPECT acquisition began 3 minutes later. Redistribution was imaged 3 to 4 hours after ${ }^{201} \mathrm{Tl}$ injection.

${ }^{201}$ TI SPECT. ${ }^{201}$ Tl SPECT imaging was performed with a single-head rotating gamma camera (Starcam; General Electric Co., Wilmington, Mass.), equiped with a low-energy, allpurpose collimator interfaced to a dedicated computer. Patients were placed in the supine position and 32 projections were obtained (step by step), 40 seconds each, through a 180-degree orbit beginning in a 45-degree right anterior oblique position and ending in a 45-degree left posterior oblique position. Images were stored in a $64 \times 64$ byte matrix. Tomographic reconstruction was performed with a filtered back-projection algorithm and a Hann filter. Oblique, orthogonal tomographic slices were used to reconstruct the left ventricle in the shortaxis, horizontal long-axis, and vertical long-axis orientations. Anterior and septal walls were considered to represent the LAD coronary artery distribution and perfusion was scored qualitatively by a consensus of three observers: $0=$ severe perfusion defect (which corresponds to $>50 \%$ of reduced uptake compared with normal region), $1=$ moderate perfusion defect $>25 \%$ and $<50 \%$ of reduced uptake compared with normal region), and $2=$ normal perfusion.

Coronary Angiography. After routine catheterization and premedication with diazepam, images were obtained in 30 -degree right anterior oblique views and 60-degree left 
Table 2. Clinical data

\begin{tabular}{|c|c|c|c|c|c|c|c|}
\hline Patient & Age $(y r) /$ sex & Prior MI & Hypertension & Diabetes & $\begin{array}{c}\text { Obesity/ } \\
\text { hyperlipidemia }\end{array}$ & $\begin{array}{c}\text { Previous } \\
\text { CABG or PTCA }\end{array}$ & $\begin{array}{l}\text { Indication } \\
{ }^{201} \text { TI SPECT }\end{array}$ \\
\hline 1 & $61 / M$ & No & No & Yes & No & Yes & Angina (at) \\
\hline 2 & $50 / M$ & No & No & No & No & No & Angina (at) \\
\hline 3 & $64 / M$ & No & Yes & Yes & No & No & LBBB only \\
\hline 4 & $73 / M$ & No & No & No & No & Yes & Angina (ty) \\
\hline 5 & $43 / M$ & No & No & No & No & No & Angina (ty) \\
\hline 6 & $77 / M$ & No & No & Yes & No & No & Angina (ty) \\
\hline 7 & $67 / M$ & No & Yes & No & No & No & Angina (ty) \\
\hline 8 & $37 / M$ & No & Yes & No & Hyperlipidemia & No & Angina (ty) \\
\hline 9 & $58 / F$ & No & No & No & Obesity & No & Angina (at) \\
\hline 10 & $59 / \mathrm{M}$ & Inferior & Yes & No & No & Yes & Angina (ty) \\
\hline 11 & $70 / F$ & No & Yes & No & No & Yes & Angina (at) \\
\hline 12 & $38 / M$ & No & Yes & No & Hyperlipidemia & No & LBBB only \\
\hline
\end{tabular}

Ml, Myocardial infarction; CABG, coronary artery bypass grafting; PTCA, percutaneous transluminal coronary angioplasty; (at), atypical; (ty), typical.

Table 3. Clinical, ${ }^{201} \mathrm{Tl}$ SPECT, and angiographic findings

\begin{tabular}{|c|c|c|c|c|c|c|c|c|c|}
\hline \multirow[b]{2}{*}{ Patient } & \multicolumn{2}{|c|}{ Resting HR (n) } & \multicolumn{2}{|c|}{ Maximum HR (n) } & \multicolumn{2}{|c|}{$\begin{array}{l}\text { Development of } \\
\text { typical angina }\end{array}$} & \multicolumn{2}{|c|}{ S/AS perfusion } & \multirow{2}{*}{$\begin{array}{c}\text { LAD } \\
>\mathbf{5 0} \%\end{array}$} \\
\hline & Exercise & Dip & Exercise & Dip & Exercise & Dip & Exercise & Dip & \\
\hline 1 & 82 & 54 & 160 & 98 & $\mathrm{~N}$ & & $1(\mathrm{PR})$ & 2 & No \\
\hline 2 & 88 & 61 & 156 & 95 & $\mathrm{~N}$ & & $0(\mathrm{PR})$ & 2 & No \\
\hline 3 & 71 & 65 & 106 & 74 & $\mathrm{~N}$ & & $1(\mathrm{RR})$ & $0(\mathrm{PR})$ & No \\
\hline 4 & 77 & 61 & 112 & 74 & $\mathrm{~N}$ & & $O(F)$ & $O(P R)$ & No \\
\hline 5 & 63 & 60 & 170 & 83 & $\mathrm{~N}$ & & $O(P R)$ & 2 & No \\
\hline 6 & $102(\mathrm{AF})$ & 115 & 151 & 145 & $\mathrm{~N}$ & & $O(F)$ & 2 & No \\
\hline 7 & 70 & 70 & 132 & 91 & Ye & & $O(F)$ & $O(F)$ & Yes $(75 \%)$ \\
\hline 8 & 60 & 65 & 180 & 95 & $\mathrm{~N}$ & & $1(\mathrm{R})$ & 2 & No \\
\hline 9 & 99 & 75 & 144 & 110 & $\mathrm{~N}$ & & $0(\mathrm{R})$ & 2 & No \\
\hline 10 & 70 & 82 & 132 & 104 & Yes & No & $0(P R)$ & $1(\mathrm{PR})$ & Yes $(70 \%)$ \\
\hline 11 & 62 & 56 & 95 & 78 & $\mathrm{~N}$ & & $1(\mathrm{R})$ & $1(\mathrm{PR})$ & Yes $(75 \%)$ \\
\hline 12 & 82 & 70 & 186 & 102 & $\mathrm{~N}$ & & $0(\mathrm{PR})$ & $\mathrm{O}(\mathrm{PR})$ & No \\
\hline
\end{tabular}

$H r$, Heart rate; Dip, dipyridamole; S/AS, septal or anteroseptal; $L A D>50 \%$, significant LAD coronary artery stenosis; 1 , moderate perfusion defect; $P R$, partially reversible; 2 , normal perfusion; $O$, severe; $R R$, reverse redistribution; $F$, fixed perfusion defect; $A F$, atrial fibrillation; $R$, reversible.

anterior oblique views (cranial and caudal orientations) and lateral views. Significant coronary artery stenosis was defined as a $50 \%$ or greater reduction in luminal diameter of any major coronary artery, primary branch, or bypass graft. A coronary artery was considered not to be compromised even in the face of significant native vessel disease if a patent bypass graft was inserted distal to the site of the lesion. Quantitative coronary angiographic analysis was performed with the ANCOR (Siemens-Elema, Solma, Sweden) system. ${ }^{19}$

\section{RESULTS}

Septal or Anteroseptal Perfusion and LAD Disease. Overall results are shown in Table 3. Six patients with exercise septal or anteroseptal perfusion defects had normal perfusion after dipyridamole (Figure 1); none of them had significant LAD coronary artery stenosis at coronary angiography. In the six patients who had only exercise perfusion defects, four defects were severe and two were moderate. The remaining six patients had 


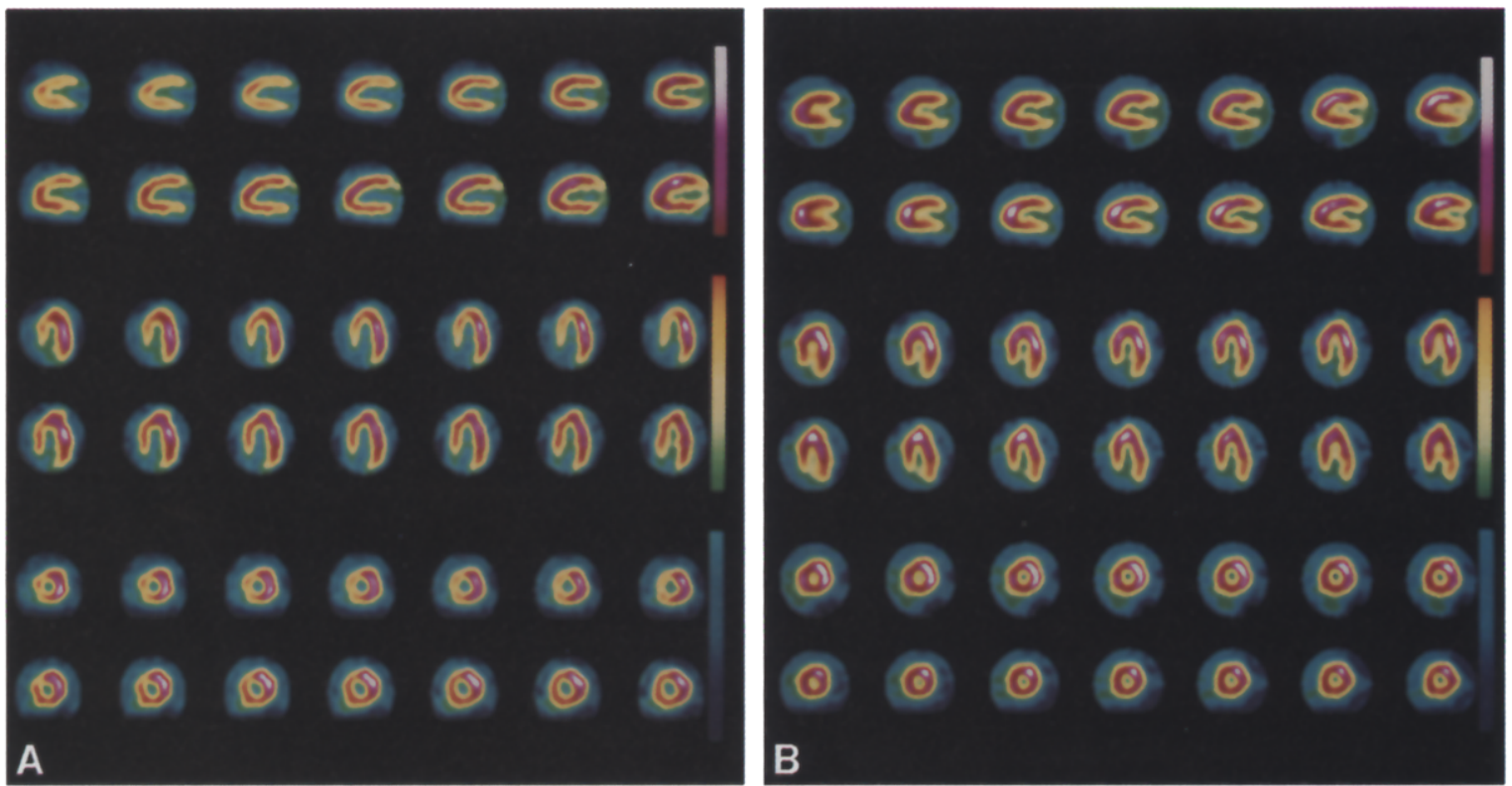

Figure 1. Patient 1. Septal perfusion defect is seen on exercise ${ }^{20} \mathrm{i}$ Tl SPECT images (A). Dipyridamole ${ }^{201} \mathrm{Tl}$ SPECT images of same patient (B) revealed normal perfusion. Coronary angiogram was normal. Rows 1,3, and 5 from top are initial images, and rows 2, 4, and 6 are redistribution images for both exercise and dipyridamole. Vertical long-axis images are arranged from septal wall to lateral wall, horizontal long-axis images from anterior wall to inferior wall, and short-axis images from apex to base.

Table 4. Overall results in patients with septal or anteroseptal perfusion defects on both exercise and dipyridamole ${ }^{201}$ TI SPECT $(n=6)$

\begin{tabular}{|c|c|c|c|c|c|}
\hline & \multicolumn{2}{|c|}{ Exercise (n) } & \multicolumn{2}{|c|}{ Dip positive (n) } & \multirow[b]{2}{*}{$\begin{array}{c}\text { Total } \\
(\mathbf{n})\end{array}$} \\
\hline & $\begin{array}{c}\text { Mod S/AS } \\
\text { defect }\end{array}$ & $\begin{array}{c}\text { Severe S/AS } \\
\text { defect }\end{array}$ & $\begin{array}{c}\text { Mod S/AS } \\
\text { defect }\end{array}$ & $\begin{array}{c}\text { Severe S/AS } \\
\text { defect }\end{array}$ & \\
\hline Patients & 2 & 4 & 2 & 4 & 6 \\
\hline Patients with LAD > $>50 \%$ & 1 & 2 & 2 & 1 & 3 \\
\hline $\begin{array}{l}\text { Patients with normal LAD } \\
\text { coronary arteries }\end{array}$ & 1 & 2 & 0 & 3 & 3 \\
\hline
\end{tabular}

Mod, moderate; S/AS, septal or anteroseptal; Dip, dipyridamole.

septal or anteroseptal perfusion defects on both exercise and dipyridamole ${ }^{201} \mathrm{Tl}$ SPECT. Shown in Table 4 are the comparative results with regard to the severity of the perfusion defect. Three of six patients with positive dipyridamole study results had significant LAD coronary artery stenosis.

Coronary arteriograms were normal in the remaining three patients who had severe septal or anteroseptal perfusion defects after dipyridamole (Figure 2).

Severity of Coronary Artery Disease. Three of 12 patients had coronary artery disease. Two patients (patients 7 and 11) had double-vessel disease; both of them had multiple scintigraphic perfusion defects with exercise and also with dipyridamole. In addition to LAD coronary artery disease, patients 7 and $11 \mathrm{had}$, respectively, $70 \%$ and $100 \%$ stenosis of the left circumflex coronary artery (also with the two grafts occluded for patient 11). The last patient had single-vessel disease.

\section{Clinical Data During Exercise and Dipyridam-} ole. Table 3 provides detailed clinical data during exercise and dipyridamole. Patients with normal dipyridamole images had a mean increase of heart rate of $77 \pm 30$ beats/min during exercise and $32 \pm 7$ beats/min during dipyridamole infusion. Those with positive dipyridamole 


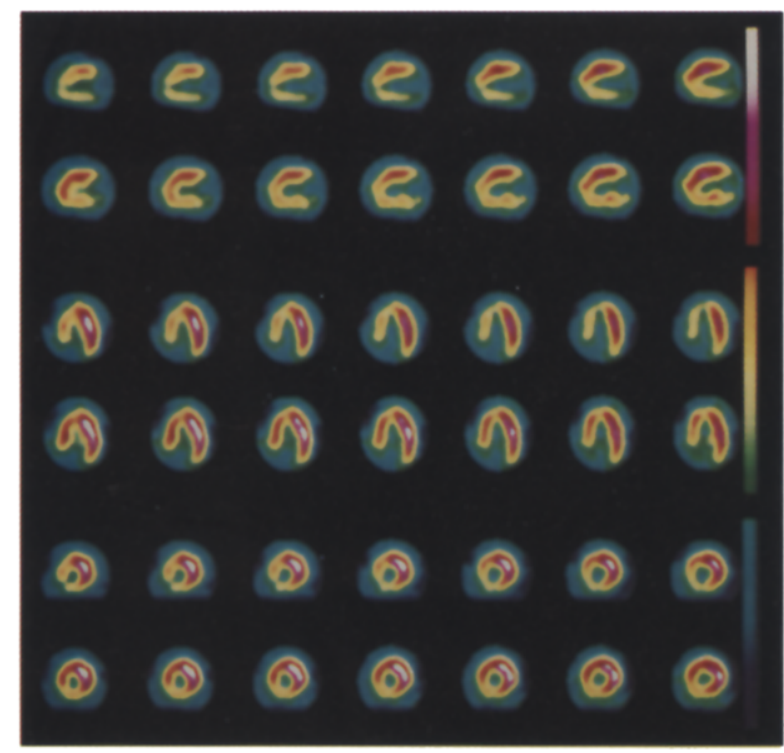

Figure 2. Dipyridamole (rows 1, 3, and 5 from top) and redistribution (rows 2, 4, and 6) ${ }^{201} \mathrm{Tl}$ SPECT images of patient 12. Severe, partially reversible septal perfusion defect, including apex, is seen; there is also inferior perfusion defect. Coronary angiogram was normal. Images are arranged as in Figure 1.

images had a mean increase of heart rate of $55 \pm 27$ beats/min during exercise and $19 \pm 8$ beats/min during dipyridamole infusion.

Analysis of False-Positive Results. Table 5 shows further analysis of false-positive results with regard to presence or absence of apical involvement, dilated left ventricles, anterior or septal wall motion abnormalities, and the mean ejection fraction value. None of these parameters could help to identify or explain false-positive results.

\section{DISCUSSION}

Our results showed that six of 12 patients with LBBB and exercise septal or anterior perfusion defects had normal scintigraphic results after dipyridamole. All six patients with normal dipyridamole ${ }^{201} \mathrm{Tl}$ SPECT results had normal coronary angiographic results. Only three of 12 patients with exercise septal or anteroseptal perfusion defects had LAD coronary artery disease. On the other hand, three of six patients with a positive dipyridamole study result had LAD coronary artery disease. These data indicate that dipyridamole ${ }^{201} \mathrm{Tl}$ SPECT was accurate in nine of 12 patients, whereas exercise was accurate in only three of 12 patients. Nevertheless, there are still false-positive results after dipyridamole with regard to the identification of patients with LBBB and underlying coronary artery disease. Moreover, only one of four patients with severe septal or anteroseptal perfusion defects after dipyridamole had LAD coronary artery disease, which indicates that the severity of the perfusion defect does not add additional information in identifying LAD coronary artery disease.

In patient 7 , exercise and dipyridamole ${ }^{201} \mathrm{Tl}$ SPECT revealed a fixed anteroseptal perfusion defect with a $75 \%$ stenosis of the LAD, without a known previous myocardial infarction. However, ventriculography showed septal dyskinesia, which suggests possible transient artery occlusion (non-Q wave myocardial infarction).

In light of the mechanisms proposed to explain perfusion defects in LBBB, ${ }^{2,6}$ their occurrence would be expected to be heart rate dependent. This was confirmed by Vaduganathan et al., ${ }^{13}$ who observed a relation between heart rate and false-positive septal defects in the exercise group. Of interest was the much lower frequency of septal defects reported during dobutamine than during exercise. ${ }^{13}$ They explain these findings by the much higher peak heart rate achieved during exercise than with dobutamine. However, the persistence of false-positive results after dipyridamole infusion confirms that factors other than heart rate contribute to abnormal septal or anteroseptal perfusion in patients with LBBB. In our study, false-positive results after dipyridamole could not be explained by higher heart rate or a larger increase in heart rate compared with patients with normal dipyridamole images (Table 3). The study by Jukema et al. ${ }^{15}$ also showed that septal dipyridamole perfusion defects were not dependent on heart rate.

In our study neither the severity nor the extent of the perfusion defect could identify patients with underlying LAD coronary artery disease: six of eight patients with severe septal or anterior perfusion defects after exercise and three of four patients with severe defects after dipyridamole had normal coronary angiograms. With regard to the extent of the perfusion defect to the apex on exercise ${ }^{201} \mathrm{Tl}$ SPECT, we could not confirm the better diagnostic accuracy reported by Matzer et al.7; among five patients who had septal or anterior perfusion defects involving the apex on exercise ${ }^{201} \mathrm{Tl}$ SPECT, only one had LAD coronary artery disease. Our findings are supported by the results of Larcos et al., ${ }^{8}$ who showed that apical extent of the exercise perfusion defect, although sensitive, was neither specific nor accurate in the identification of patients with coronary artery disease. Apical involvement was also of no help for dipyridamole in our study; among the three patients with false-positive findings for LAD coronary artery disease, two had perfusion defects involving the apex. The recent study of Vaduganathan et al. ${ }^{13}$ reported the results of the largest series to date of patients with LBBB undergoing myocardial perfusion scintigraphy with three different modalities of stress. They did not find value in the size of the 
Table 5. Analysis of false-positive results

\begin{tabular}{lccccc}
\hline & \multicolumn{2}{c}{ False positive } & & \multicolumn{2}{c}{ Other patients } \\
\cline { 2 - 5 } & $\begin{array}{c}\text { Exercise } \\
(\mathbf{n}=\mathbf{9})\end{array}$ & $\begin{array}{c}\text { Dipyridamole } \\
(\mathbf{n = 3 )}\end{array}$ & $\begin{array}{c}\text { Exercise } \\
(\mathbf{n = 3})\end{array}$ & $\begin{array}{c}\text { Dipyridamole } \\
(\mathbf{n}=\mathbf{9})\end{array}$ \\
\hline Apical involvement $(n)$ & $4 / 9$ & $2 / 3$ & $1 / 3$ & $1 / 9$ \\
Dilated left ventricle $(n)$ & $2 / 9$ & $0 / 3$ & $1 / 3$ & $3 / 9$ \\
Mean ejection fraction $(\%)$ & 54 & 54 & 60 & 57 \\
$\begin{array}{l}\text { Anterior or septal wall } \\
\text { motion abnormalities }\end{array}$ & $4 / 9$ & $1 / 3$ & $3 / 3$ & $6 / 9$ \\
\hline
\end{tabular}

perfusion defect or the involvement of the anterior wall, the apex, or another territory in differentiating true from false-positive cases during exercise. They also reported a higher left ventricular ejection fraction in the subgroup of patients who exercised and had false-positive scan responses compared with those with true positive scan results.

Hodge et al. ${ }^{20}$ suggested that dilated left ventricles may be responsible for false-positive results in patients with LBBB. In our study, only two of nine patients with false-positive results after exercise and none of three patients with false-positive results after dipyridamole had dilated left ventricles. Therefore we could not confirm this hypothesis.

Our results are in agreement with those of previous studies, ${ }^{6.12-18}$ which showed that septal or anteroseptal perfusion defects in patients with LBBB are less frequent with pharmacologic stress, thereby improving the specificity of thallium scintigraphy in those patients. Few studies, however, compared dipyridamole (or adenosine) and exercise in the same patients. In this study, only patients with abnormal septal or anteroseptal perfusion on exercise ${ }^{201}$ Tl SPECT underwent dipyridamole stress, whereas in the other comparative studies ${ }^{6,11-14}$ patients without perfusion defects on the exercise study also underwent dipyridamole scintigraphy. Because the limitation with exercise is the high number of false-positive results, we chose to evaluate dipyridamole in patients with positive exercise scintigrams. Analysis in our study of clinical data, results of ${ }^{201} \mathrm{Tl}$ SPECT in terms of severity and extent of perfusion defect or dilated left ventricle, and ventriculographic and coronary arteriographic findings could not explain the false-positive scintigraphic results or help to identify patients with underlying coronary artery disease.

There are several hypotheses to explain the mechanism for abnormal perfusion in LBBB. Grines et al. ${ }^{23}$ reported that altered electrical activation as a result of LBBB is responsible for global ventricular abnormalities that could lead to abnormal septal motion and abnormal left ventricular ejection. The occurrence of "relative hypoperfusion" caused by the abnormal septal motion that could cause a prolonged compression of the septal arteries has been proposed by Hirzel et al. ${ }^{2}$ Another explanation for this relative hypoperfusion has been proposed by Burns et al. ${ }^{6}$ They postulated that in patients with LBBB the septum contracts in early systole with low tension to overcome right ventricular rather than left ventricular outflow resistance as it occurs with normal conduction; therefore the septal wall will receive less coronary flow as a result of coronary autoregulation. Ono et al. ${ }^{24}$ used an in vivo animal model to determine whether LBBB itself induces abnormal myocardial perfusion and ischemia. They demonstrated that during LBBB the mean septal intramyocardial pressure increased significantly in the $T_{D}$ phase, which may result in reduced myocardial perfusion in the septum. Nevertheless, they did not observe indirect signs of myocardial ischemia such as increased septal glucose uptake or lactate production. In view of these data, perfusion of the septal or anteroseptal territories may be reduced for functional rather than anatomic reasons and the so-called false-positive ${ }^{201} \mathrm{Tl}$ study results might well demonstrate relative hypoperfusion.

The occurrence of septal or anteroseptal perfusion defects is obviously not restricted to the use of ${ }^{201} \mathrm{Tl}$. Results are somewhat conflicting on the occurrence of septal or anterior defects with exercise sestamibi. Altehoefer et al. ${ }^{21}$ postulated that ${ }^{99 \mathrm{~m}} \mathrm{Tc}$-labeled sestamibi scintigraphy could be more accurate for the detection of coronary artery disease in patients with LBBB because most of these patients $(55 \%)$ revealed normal septal uptake. However, the findings of Knapp et al. ${ }^{22}$ differ because they described a septal defect (reversible or not) on ${ }^{99 \mathrm{~m}} \mathrm{Tc}$-labeled sestamibi scintigraphy in $34(91.8 \%)$ of 37 patients. In both studies the authors speculated that the reversibility of the defect could identify patients with coronary artery disease. Nevertheless, false-positive results with sestamibi according to the criterion of reversibility have been described. ${ }^{25,26}$ Another study ${ }^{11}$ revealed 
the conflicting results of ${ }^{99 \mathrm{~m}} \mathrm{Tc}-$ labeled sestamibi scintigraphy in LBBB. In this study, Ebersole et al., ${ }^{11}$ who compared exercise and adenosine stress, pointed out that the specificity in the territory of the LAD coronary artery was only $25 \%$ with exercise, whereas that for adenosine was $87.5 \%$. Moreover, in their study, all but one patient who had false-positive results with exercise had a reversible defect, which confirms that the criterion of reversibility could not help to identify patients with LBBB and underlying coronary artery disease. They also conclude by using ${ }^{99 \mathrm{~m}} \mathrm{Tc}$-labeled sestamibi scintigraphy to the improved specificity of pharmacologic stress compared with exercise.

Limitation of the Method. It can be argued that tomographic analysis in our study was qualitative. However, very good correlations between visual and quantitative analysis have been described. The superiority of the quantitative analysis has not been proved clearly, and there is no significant difference (statistically significant) between the two modalities of analysis. ${ }^{27}$ In fact, the problem with myocardial scintigraphy in patients with LBBB is the high frequency of perfusion defects in the absence of LAD artery disease, which means that the specificity of thallium scintigraphy in detection of LAD disease is of concern. It is known that quantitative analysis is equivalent to or lower than visual analysis in this setting. ${ }^{27-30}$ Moreover, even with quantitative analysis, several studies ${ }^{4-6,8,12,13}$ reported the low specificity of exercise ${ }^{201} \mathrm{Tl}$ scintigraphy in detecting LAD coronary artery disease in patients with LBBB. Last, in our study, six of eight and three of four patients with severe perfusion defects (which means clearly positive results) after, respectively, exercise and dipyridamole had normal coronary arteries. Quantitative analysis cannot help increase diagnostic accuracy in these patients.

Conclusion. In view of the cumulative results of exercise scintigraphy and the conflicting results with other alternatives (apical involvement and exercise sestamibi), pharmacologic stress by either dipyridamole or adenosine seems the preferred choice to exercise scintigraphy in patients with LBBB, by reducing the number of so-called false-positive results. In case of normal perfusion with dipyridamole, coronary artery disease can reasonably be excluded and there is no real indication to perform coronary angiography; therefore the number of coronary angiograms in patients with LBBB may be reduced by use of pharmacologic stress. However, even severe septal or anteroseptal perfusion defects on dipyridamole studies may occur in the absence of LAD coronary artery disease. The presence or absence of apical involvement, dilated left ventricles, decreased left ventricular ejection fraction, or wall motion abnormalities could not help in the identification of patients with false-positive results. Coronary angiography is thus still indicated in studies with positive results to identify patients with underlying coronary artery disease, a major prognostic factor in patients with LBBB.

\section{References}

1. Mc Gowan LR, Welch TG, Zaret BL, Bryson AL, Martin ND, Flamm MD. Noninvasive myocardial imaging with potassium-43 and rubidium- 81 in patients with left bundle branch block. Am $\mathbf{J}$ Cardiol 1976;38:422-8.

2. Hirzel HO, Senn M, Nuesch K, Buettner C, Pfeiffer A, Hess OM, et al. Thallium-201 scintigraphy in complete left bundle branch block. Am J Cardiol 1984;53:764-9.

3. Huerta EM, Rodriguez, Padial L, Castro Beiras JM, Illera JP, Asin Cardiel E. Thallium-201 scintigraphy in patients having complete left bundle branch block with normal coronary arteries. Int J Cardiol 1987;16:43-6.

4. Rothbart MR, Beller GA, Watson DD, Nygaard TW, Gibson RS. Diagnostic accuracy and prognostic significance of quantitative thallium-201 scintigraphy in patients with left bundle branch block. Am J Noninvas Cardiol 1987;1:197-205.

5. DePuey EJ, Guertler-Krawcynska E, Robbins WL. Thallium-201 SPECT in coronary artery disease patients with left bundle branch block. J Nucl Med 1988;29:1479-85.

6. Burns RJ, Galligan L, Wright LM, Lawand L, Burke RJ, Gladstone PJ. Improved specificity of myocardial thallium-201 single-photon emission computed tomography in patients with left bundle branch block by dipyridamole. Am J Cardiol 1991;68:504-8.

7. Matzer L, Kiat H, Friedman JD, Van Train K, Maddahi J, Berman DS. A new approach to the assement of tomographic thallium-201 scintigraphy in patients with left bundle branch block. J Am Coll Cardiol 1991;17:1309-17.

8. Larcos G, Gibbons RJ, Browm ML. Diagnostic accuracy of exercise thallium-201 single photon emission computed tomography in patients with left bundle branch block. Am J Cardiol 1991;68:756-60.

9. La Canna G, Giubbini R, Metra M, Arosio G, Curnis A, Cicogna $\mathrm{R}$, et al. Assessment of myocardial perfusion with thallium-201 scintigraphy in exercise-induced left bundle branch block: diagnostic value and clinical significance. Eur Heart J 1992;13;942-6.

10. Delonca J, Camenzid E, Meier B, Righetti A. Limits of thallium201 exercise scintigraphy to detect coronary disease in patients with complete and permanent bundle branch block: a review of 134 cases. Am Heart J 1992;123:1201-7.

11. Ebersole DG, Heironimus J, Toney MO, Billingsley J. Comparison of exercise and adenosine technetium- $99 \mathrm{~m}$ sestamibi myocardial scintigraphy for diagnosis of coronary artery disease in patients with left bundle branch block. Am J Cardiol 1993;71:450-3.

12. O'Keefe JH, Bateman TM, Barnhart CS. Adenosine thallium-201 is superior to exercise thallium-201 for detecting coronary artery disease in patients with left bundle branch block. J Am Coll Cardiol 1993;21:1332-8.

13. Vaduganathan P, Zuo-Xiang HE, Raghavan C, Mahmarian JJ, Verani MS. Detection of left anterior descending coronary artery stenosis in patients with left bundle branch block: exercise, adenosine or dobutamine imaging? J Am Coll Cardiol 1996;28: $543-50$.

14. Morais J, Soucy JP, Sestier F, Lamoureux F, Lamoureux J, Danais $S$. Dipyridamole testing compared to exercise stress for thallium201 imaging in patients with left bundle branch block. Can J Cardiol 1990;1:5-8.

15. Jukema JW, Van der Wall EE, Van der Vis-Melsen MJE, Kruyswijk HH, Bruschke AVG. Dipyridamole thallium-201 scintigraphy for improved detection of left anterior descending coro- 
nary artery stenosis in patients with left bundle branch block. Eur Heart J 1993; 14:53-6.

16. Rockett JF, Wood WC, Moinuddin M, Loveless V, Parrish B. Intravenous dipyridamole thallium-201 SPECT imaging in patients with left bundle branch block. Clin Nucl Med 1990;15:401-7.

17. Larcos G, Brown MI, Gibbons RJ. Role of dipyridamole thallium201 imaging in left bundle branch block. Am J Cardiol 1991;68: $1097-8$.

18. Patel R, Bushnell DL, Wagner R, Stumbris R. Frequency of false positive septal defects on adenosine ${ }^{201} \mathrm{Tl}$ images in patients with left bundle branch block. Nucl Med Commun 1995;16:137-9.

19. Pope DL, Parker DL, Gustafson DE, Clayton PD. Dynamic search algorithms in left ventricular border recognition and analysis of coronary arteries. Comp Cardiol 1984;4:71-5.

20. Hodge J, Mattera J, Fetterman R, Williams B, Wackers FJ. False positive TL-201 defects in left bundle branch block: relationship to left ventricular dilatation. J Am Coll Cardiol 1987;9:137A

21. Altehoefer C, Vom Dahl J, Kleinhans E, Uebis R, Hanrath P, Buell $\mathrm{U}$. ${ }^{99 \mathrm{~m}} \mathrm{Tc}$-methoxyisobutylisonitrile stress/rest SPECT in patients with constant complete left bundle branch block. Nucl Med Commun 1993; 14:30-5.

22. Knapp WH, Bentrup A, Schmidt U, Ohlmeier H. Myocardial scintigraphy with thallium-201 and technetium-99m-hexakis-methoxyisobutilisonitrile in left bundle branch block: a study in patients with and without coronary artery disease. Eur J Nucl Med 1993;20:219-24.

23. Grines CL, Bashore TM, Boudoulas H, Olson S, Shafer P, Wooley CF. Functional abnormalities in isolated left bundle branch block: the effect of interventricular asynchrony. Circulation 1989;79:84553.

24. Ono S, Nohara R, Kambara H, Okuda K, Kawai C. Regional myocardial perfusion and glucose metabolism in experimental left bundle branch block. Circulation 1992;85:1125-31.

25. Campeau RJ, Garcia OM, Colon R, Agusala M, Correa OA. False positive Tc-99m sestamibi SPECT in a patient with left bundle branch block. Clin Nucl Med 1993;18:40-2.

26. Altehoefer C, Vom Dahl J, Bull U. Falsch-positiver Befund in der $\%$ Tc-MIBI SPECT bei Linksschenkelblock und angiographisch ausgeschlossener KHK. Nucl Med 1994;33:46-8.

27. Iskandrian AS, Verani MS. Nuclear cardiac imaging: principles and applications. Philadelphia: FA Davis, 1996:114-7.

28. Tamaki N, Yoshiharu Y, Mukai T, Kodama S, Kadota K, Kambara $\mathrm{H}$, et al. Stress thallium-201 transaxial emission computed tomography: quantitative versus qualitative analysis for evaluation of coronary artery disease. J Am Coll Cardiol 1984:4:1213-21.

29. DePasquale EE, Nody AC, DePuey EG, Garcia EV, Pilcher G, Bredlean C, et al. Quantitative rotational thallium-201 tomography for identifying and localizing coronary artery disease. Circulation 1988;77:316-27.

30. Mabmarian JJ, Boyce T, Goldberg RK, Cocanougher MK, Roberts R, Verani MS. Quantitative exercise thallium-201 single photon emission computed tomography for the enhanced diagnosis of ischemic heart disease. J Am Coll Cardiol 1990;15:318-29.

31. Braat SH, Brugada P, Bar FW, Gorgels APM, Wellens HJJ. Thallium-20l exercise scintigraphy and left bundle branch block. Am J Cardiol 1985;55:224-6. 